\title{
BUILDING EVIDENCE AND SUPPORT FOR A STRATEGY TO COUNTER SMOKING IMAGES IN MOVIES
}

\section{Wendy Oakes}

The Cancer Council New South Wales

\section{Christine Edwards}

Health Promotion

North Sydney Central Coast Area Health Service

An increasing body of research indicates that the attractive portrayal of smoking in movies is a factor in the uptake of smoking by young people. Indeed, a recent study by Sargent et $a l^{1}$ suggests that in the United States, exposure to movie smoking is the primary independent risk factor for smoking initiation in adolescents aged 10 to 14 years, accounting for smoking initiation in more than one third of this group.

A number of interventions have been suggested to counter this effect. Screening an anti-smoking advertisement before a movie that contains excessive or attractive images of smoking (counter advertising) is currently supported by the best level of evidence. Consequently, the Cancer Council New South Wales has committed to advocating for counter advertising to become health policy in NSW.

However, while health research may provide a high level of evidence that a particular public health intervention will result in real health benefits to the community, this is rarely the only determining factor in the decision to use the intervention. In order for counter advertising to become incorporated into policy and practice, the agreement of stakeholders outside the health sector (including the arts and film industries) is required.

The needs of the different stakeholders create a complex dynamic, with research informing the development of an advocacy position. This, in turn, highlights obstacles to implementation of the intervention, which can often only be solved through further research. This paper is a case study of the co-operation between researchers, policy makers, health promotion staff and a non government organisation to contribute to the current research on counter advertising, thus building a case and harnessing support for a counter advertising policy to be implemented in NSW.

\section{THE IMPACT OF SMOKING IN MOVIES AND POSSIBLE POLICY RESPONSES}

Banning tobacco advertising in cinemas and on television in Australia in the 1970s was an early public policy response to the impact of glamorous film images on smoking rates. However, smoking continues to exert its seductive influence. Instead of one 45-second advertisement before a movie in your local cinema, there is now an average of 12 smoking scenes in the movie itself, many featuring the latest celebrity. ${ }^{2}$ There is growing evidence that the impact of this on audiences, and especially on young audiences, is the same as that of tobacco advertising. This evidence shows that:
- High exposure to smoking in movies increases the risk of viewers taking up smoking by 2.71 times in the 10-14 years age group. ${ }^{2}$

- Adolescents (14-15 years) are more likely to report positive attitudes to smoking after seeing smoking portrayed in movies, increasing the risk that they will take up smoking. ${ }^{3}$

- Teenagers whose favourite stars smoke on screen are up to three times more likely to smoke than those whose favourite stars do not smoke. ${ }^{4}$

- Teenagers whose favourite stars smoke are 16 times more likely to think favourably of smoking, increasing the risk they will take up smoking. ${ }^{4}$

Tobacco control advocates have suggested several ways to counter this influence. The American Legacy Foundation, the World Health Organization and a number of other United States health organisations, for example, support four 'Smoke Free Movies Principles':

1. Rate new smoking movies ' $R$ ' (the US ' $R$ ' rating means that under 17-year-olds must be accompanied by a parent or adult guardian)

2. Require a credit at the end of the movie certifying that no payment has been received for showing smoking

3. Require strong antismoking advertisements be shown before the movie

4. Stop identifying brands.

From a health impact perspective, it is irrelevant whether the smoking scenes are a result of tobacco industry product placement or the creative choice of the director, producer or actor. Research has provided evidence that clearly points to a relationship between exposure to glamorised smoking images in movies, and smoking rates amongst young people.

There is also a good level of evidence demonstrating that showing anti-smoking advertisements before a movie will affect young people's attitudes to the smoking they see in movies. ${ }^{3}$ However, to move from research evidence to public policy and then to the practical implementation of a counter advertising strategy in NSW will require collaboration across government and commercial sectors in health and arts portfolios, and involve politicians, policy makers and commercial interests in the film industry.

Non government organisations interested in tobacco control, such as the Cancer Council New South Wales, can help to bring these partners together by gathering evidence, demonstrating the effect of proposed policies through test or pilot interventions, creating public awareness of the issue and harnessing public support for the solution.

The Cancer Council New South Wales has approached its advocacy position in the following systematic way. 


\section{Gathering evidence that smoking in movies is a problem}

A literature review has shown that there is now a strong body of evidence in the peer reviewed literature that exposure to smoking in movies increases the risk that young people will take up smoking. ${ }^{1,2,3}$ In addition, a survey of the health behaviour of secondary school students conducted by NSW Health showed that 49 per cent of the young people surveyed thought that celebrities' smoking encourages young people to take up smoking. ${ }^{5}$

\section{Gathering evidence that counter advertising could be effective in dealing with the problem}

While published research supports counter advertising as an effective way to counter attractive images in movies of smoking ${ }^{3,6}$, the Cancer Council decided to participate in further research in local cinemas to build on this evidence. Together with the former Central Coast Health, the former Central Sydney, South West Sydney, Northern Sydney, Northern Rivers and Macquarie area health services conducted research in real life situations to test the effectiveness of counter advertising among 12- to 20year-old, male and female moviegoers. The test screening of a counter advertisement in cinemas also allowed us to assess the feasibility of implementing counter advertising as an on-going public health intervention.

The Cancer Council produced a new cinema advertisement designed to alert viewers to the smoking in the movie they were about to watch, with the message 'Don't be sucked in by the movie you are about to see'. The advertisement was shown before the movies Alfie and Closer across 21 locations around NSW; Cancer Council staff, area health service staff and volunteers conducted exit surveys using the methodology developed by Edwards et al. ${ }^{3}$

The results of this research have described the effectiveness of the intervention and the feasibility of implementing counter advertising. The advertisement was successful in reducing approval of smoking in the movie in 12- to 17year-old non-smokers. ${ }^{7}$ This is a potentially useful health outcome as approval of smoking is a risk factor for future smoking uptake. ${ }^{8}$

\section{Assessing practical issues and possible obstacles (a) The availability of effective advertisements}

Both policy makers and commercial interests will want to know whether a counter advertising policy will require the use of specially produced advertisements, which could significantly add to the cost of implementation. There is currently field research providing evidence of the effectiveness of two types of advertisements that reference smoking in an upcoming movie. ${ }^{3,6}$ However, US studies that used a range of anti-smoking advertisements in a classroom situation suggest that other anti-smoking advertisements would also work. A number of anti-smoking mass media campaigns are planned for 2006 and the Cancer Council will investigate the possibility of these being used for further research on the effectiveness of different advertisement messages in cinemas.

\section{(b) Selection of movies that require counter advertising} The Cancer Council New South Wales is not advocating a total ban of all smoking images in all movies. In fact, some movies may enhance anti-smoking messages by portraying the damaging effects of smoking. The major concern of tobacco control advocates is smoking that:

- is portrayed as desirable, attractive, rebellious or normal, especially to youth audiences

- is portrayed unrealistically, for example in locations where smoking is normally prohibited or among nonsmokers who would normally object

- is portrayed at unrealistically high levels

- shows cigarette brands.

The Cancer Council believes that no further research is required before counter advertising could be introduced. The Office of Film and Literature Classification already has a process by which it rates violence, coarse language and sexual activity and the same sorts of processes could be used to achieve a rating system for smoking that would indicate which films require counter advertising.

(c) Who should be responsible for ensuring that anti-smoking advertisements appear with appropriate movies?

The answer to the question of who should be responsible for ensuring that anti-smoking advertisements appear with appropriate movies will not be solved by health research, irrespective of the quality. Good quality pilot programs, however, will help identify solutions to some of the practical issues involved in putting the strategy into practice and will also help to reassure stakeholders, such as the film industry, that this can be achieved. A simple short-term answer to the question of responsibility could be that governments - either federal or state-who run anti-smoking campaigns could include cinema as part of their media package.

The Cancer Council's preferred option is that film distributors in NSW be legally required to provide notification of their intention to screen any film that meets the criteria for unacceptable smoking and that the cinema screening the film be required to show an approved antismoking advertisement before the movie.

\section{Gathering support for counter advertising}

\section{(a) Public reaction}

One vital step in the journey from research to policy and practice is acquiring the support of the general population. Strong community concerns about smoking issues can drive political will and thus policy change and, equally, a lack of community interest can result in policies not being implemented.

Collaborative research is again providing support for advocates on this issue. The Centre for Health Research 
and Psycho-oncology (CHeRP), which is jointly funded by Newcastle University and the Cancer Council New South Wales, has surveyed the community's awareness of smoking in movies and its support for government action to counter it. The results from this survey and future community surveys will inform the Cancer Council's advocacy strategies and provide a measure of the success of awareness activity.

\section{(b) Product champion}

Evidence and health policy will not be enough to ensure that counter advertising is put into practice. The arts and film industries are key stakeholders with strong political connections and the potential power to block any proposed interventions. Therefore, an essential supporter in the advocacy campaign will be a 'champion' from the film industry who is prepared to lend their support publicly and introduce health advocates to the key players from the arts and film industries. The Cancer Council has already received support and assistance from individuals in the film industry and will continue this discussion to identify a champion for the campaign.

\section{CONCLUSION}

To move counter advertising from being a good evidencebased theoretical strategy into practice will require collaboration across a number of sectors. By working collaboratively, public health research, health promotion and advocacy groups can combine their respective strengths to present a feasible solution that is not only based on sound evidence but will also satisfy the many technical and practical issues involved in implementing the strategy.

\section{REFERENCES}

1. Sargent JD et al. Exposure to movie smoking: Its relation to smoking initiation among US adolescents. Pediatrics 2005; 116: 1183-91.

2. American Lung Association of Sacramento-Emigrant Trails. STARS movie data summary for top-ten weekly movies reviewed from May 312002 - May 26 2003. Available at www.scenesmoking.org/STARS\%200ne\%20Year\%20Data. pdf. Accessed 14 January 2004

3. Pechmann C, Shih CF. Smoking scenes in movies and antismoking advertisements before movies: Effects on youth. Journal of Marketing 1999; 63: 1-13.

4. Tickle JJ, Sargent JD, Dalton MA, Beach ML, Heatherton TF. Favourite movie stars, their tobacco use in contemporary movies, and its association with adolescent smoking. Tobacco Control Spring 2001; 10: 16-22.

5. Centre for epidemiology and research, NSW Department of Health. The health behaviours of secondary school students in New South Wales, 2002. NSW Public Health Bull 2004; 15(S-2).

6. Edwards CA. Out of the Smokescreen: Does an anti-smoking advertisement affect young women's perception of smoking in movies and their intention to smoke? Tobacco Control 2004; 13; 277-82.

7. Edwards CA, Oakes W, Bull D. Out of the Smokescreen II: The effect of The Cancer Council NSW anti-smoking advertisement on young people's perception of smoking in movies and their intention to smoke. Report. The Cancer Council New South Wales; Oct 2005.

8. Chassin L, Presson C, Bensenberg M, Corty E, Olshavsky $\mathrm{R}$, Sherman S. Predicting adolescents' intention to smoke cigarettes, Journal of Health and Social Behaviour 1981; 22 (Dec): 445-55. 